DOI : 10.31357/fhssmst.2009.00664

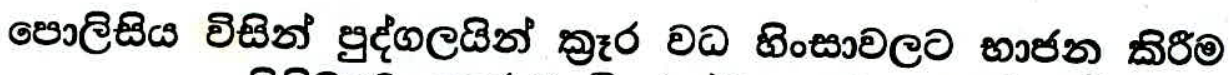

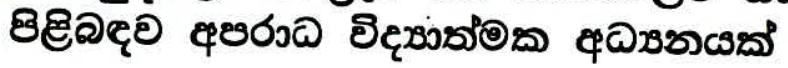

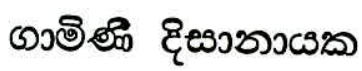

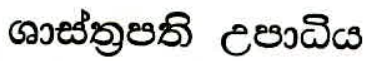




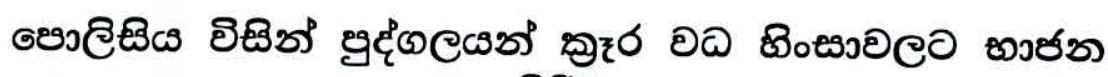
ฉిరిఠ

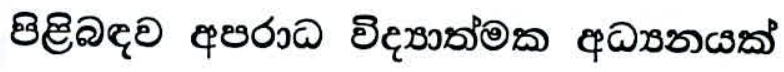

\begin{tabular}{|c|c|}
\hline 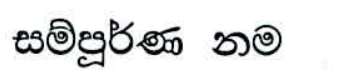 & 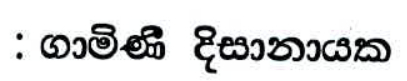 \\
\hline 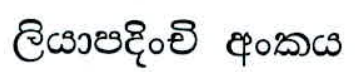 & :GS/SS/2300/2004 \\
\hline อВళםs & : 2004/2005 \\
\hline
\end{tabular}

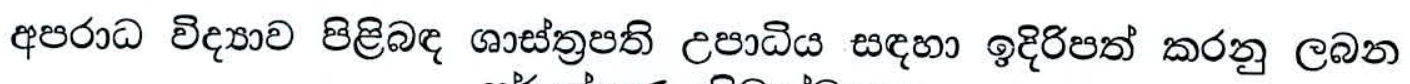

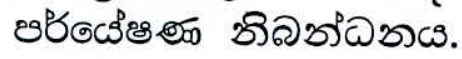

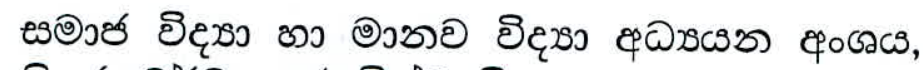

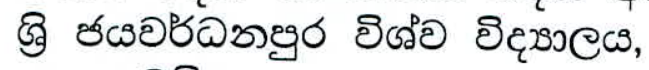
ตంఠตJอలిల,

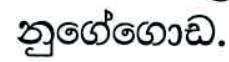



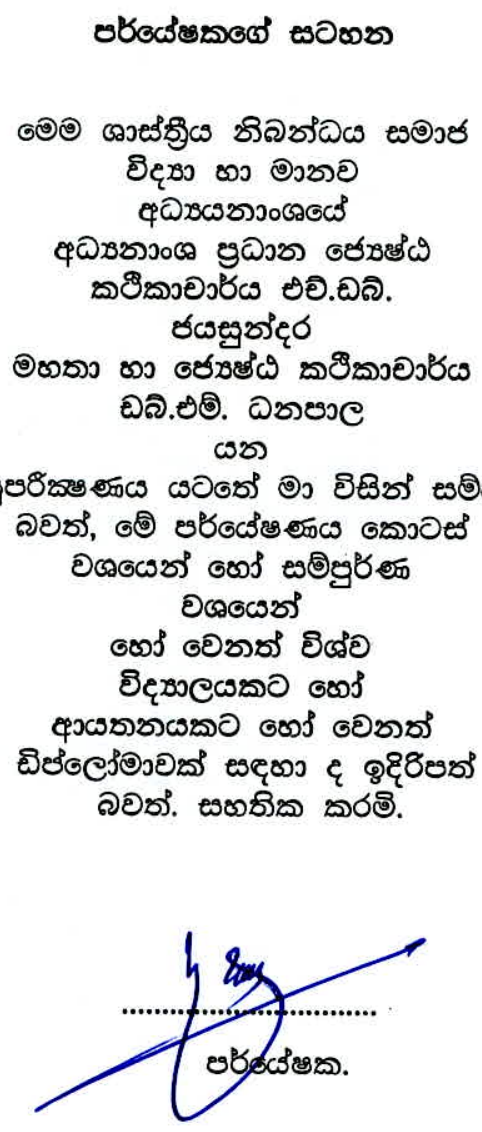


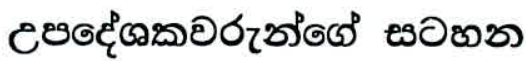

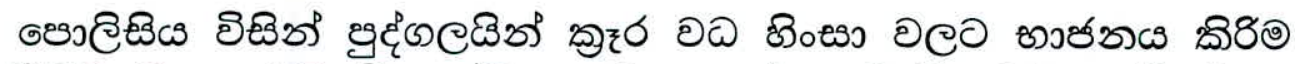

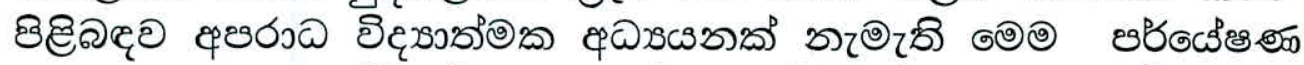

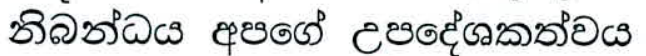

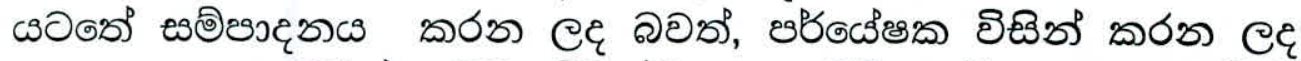

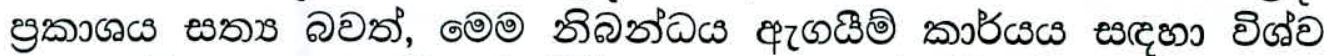

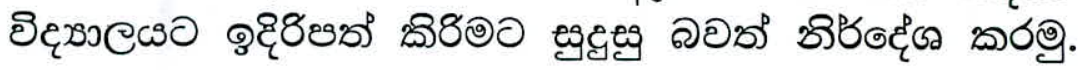

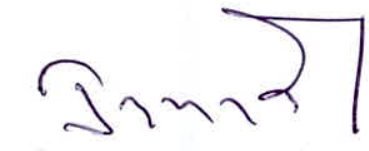

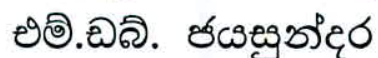

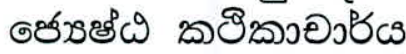

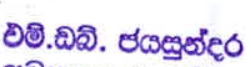

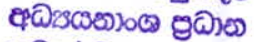

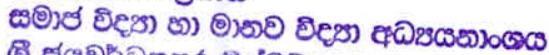

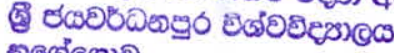

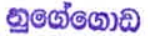

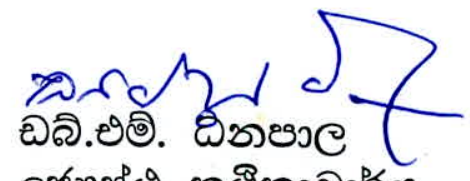

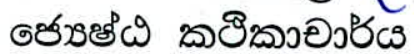

This is to certify that Mr. Gramini Bissanayaka has done

all the Corrections, additions s amendments in accordance with the Comments \& Suggestions at the examiners.
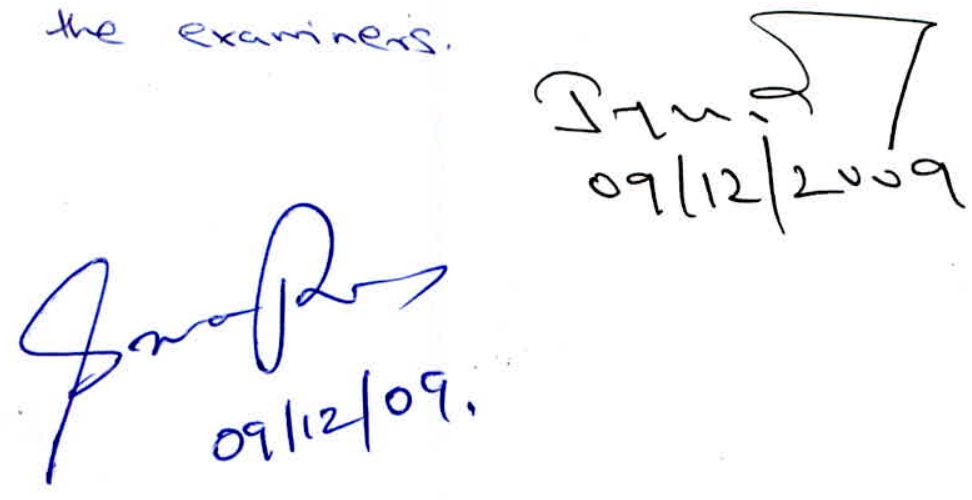


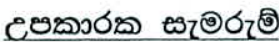

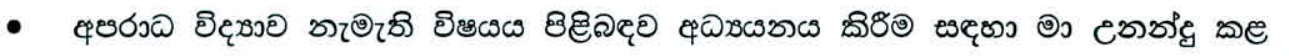

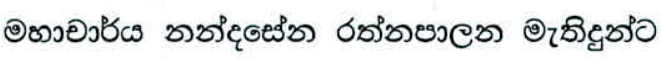

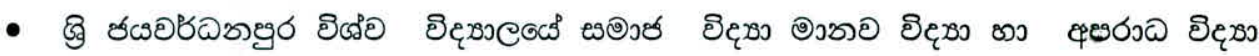

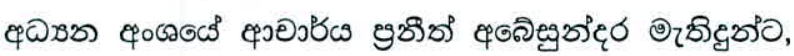

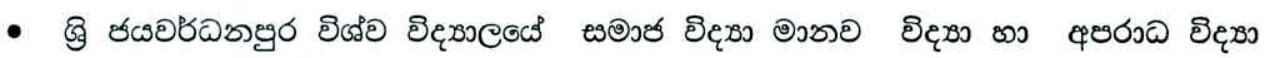

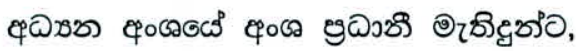

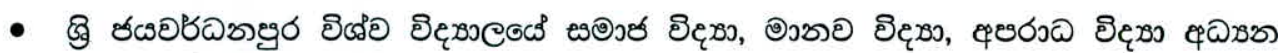

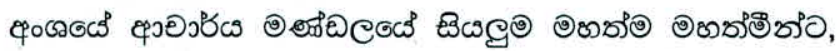

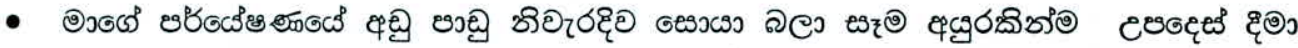

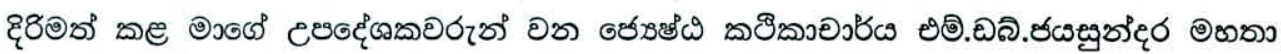

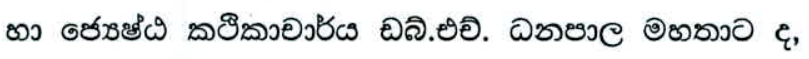

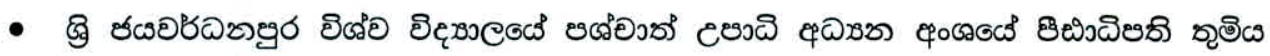

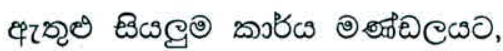

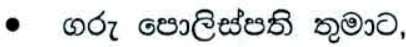

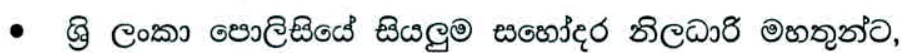

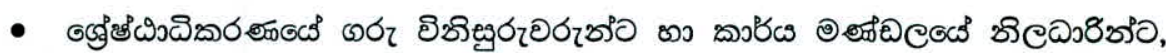

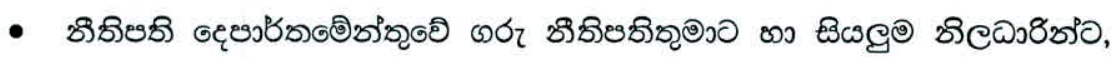

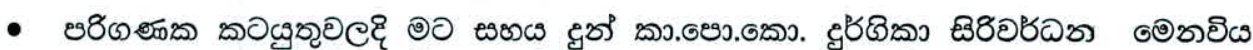

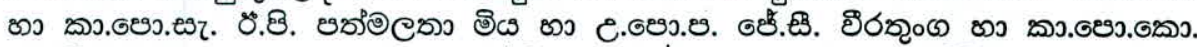

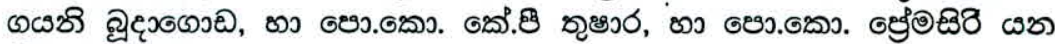
หిలదงชั่อ,

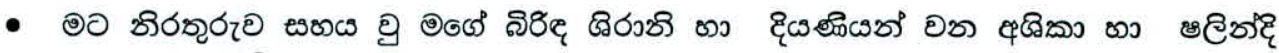

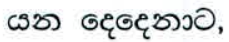

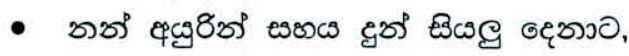

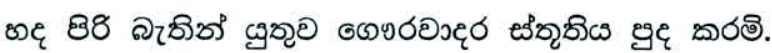




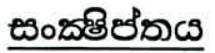

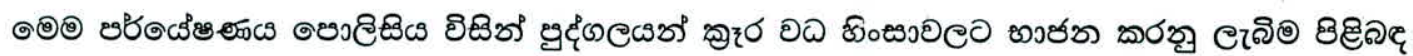

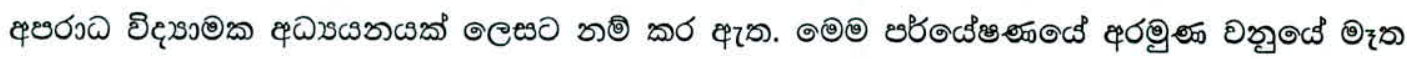

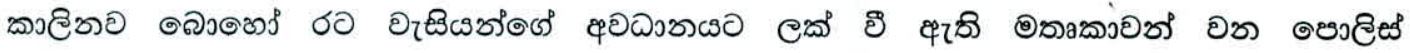

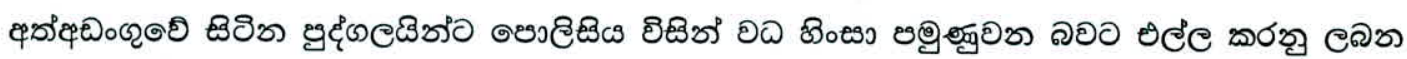

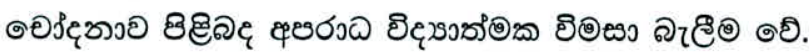

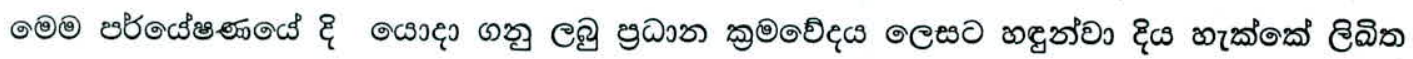

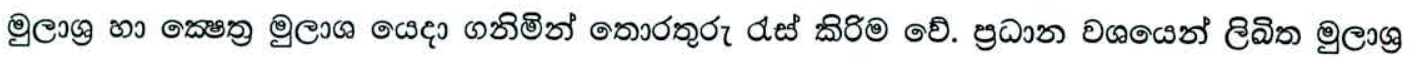

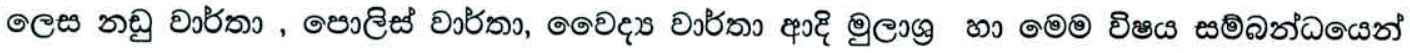

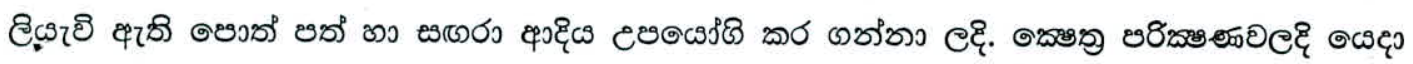

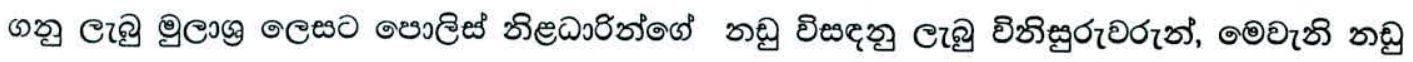

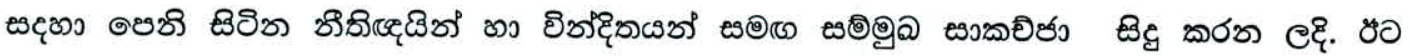

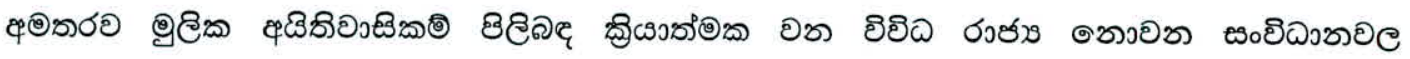

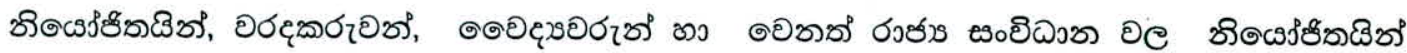

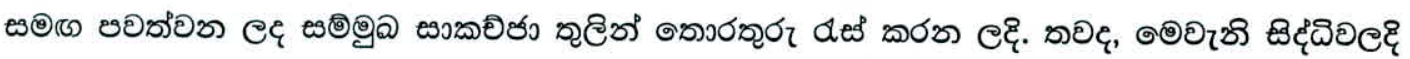

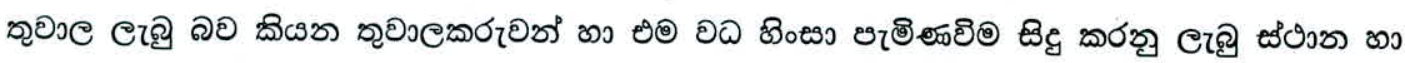

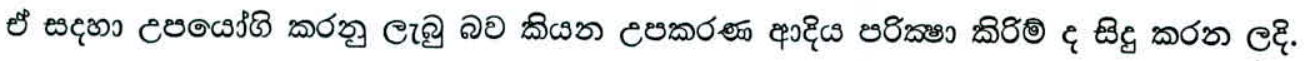

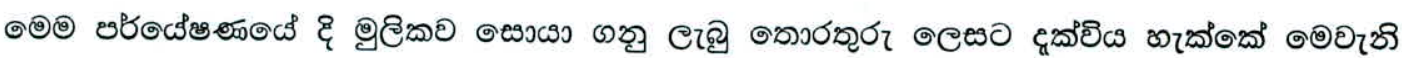

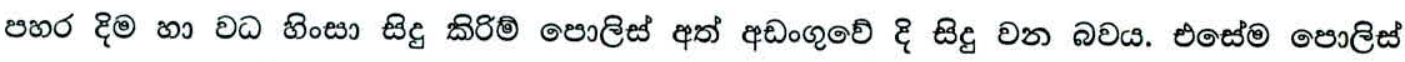

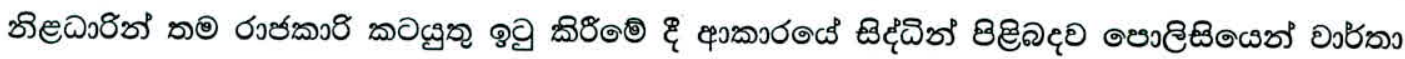

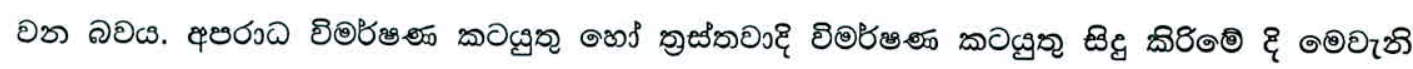

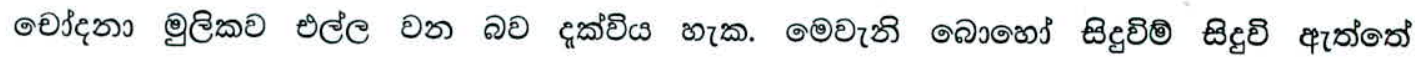

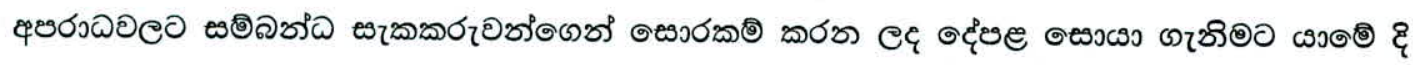

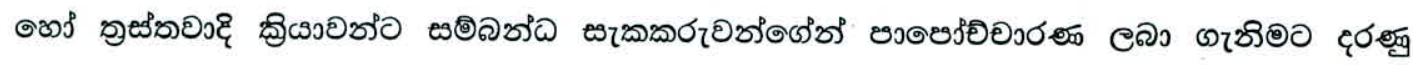

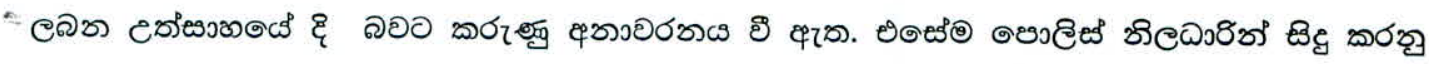

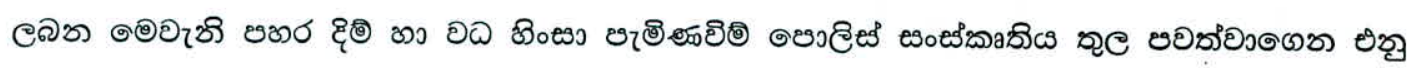




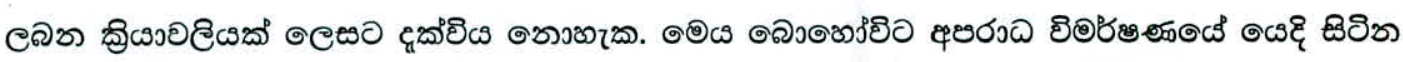

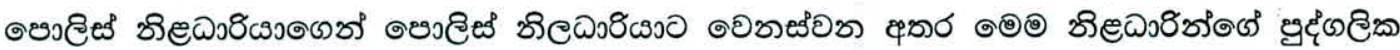

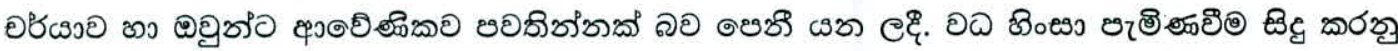

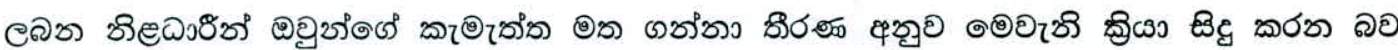

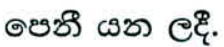

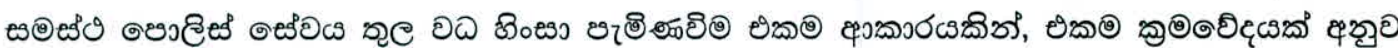

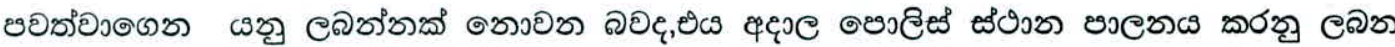

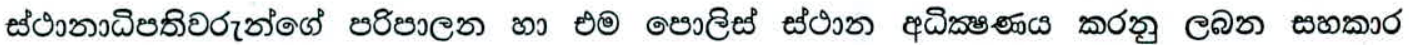

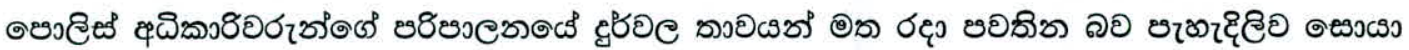

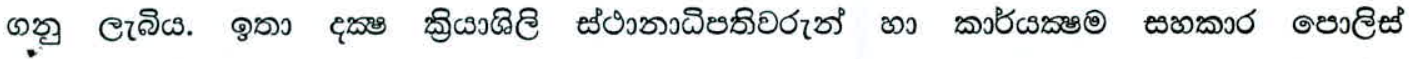

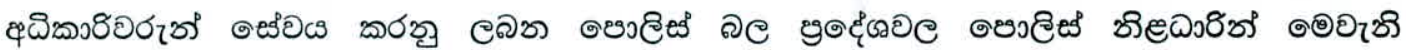

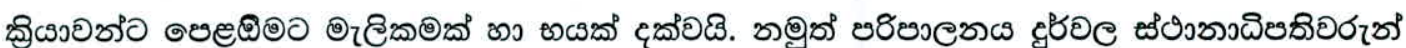

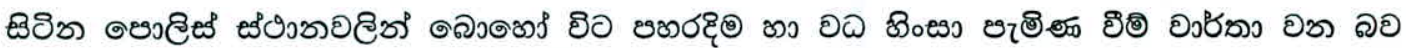

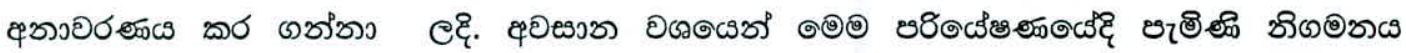

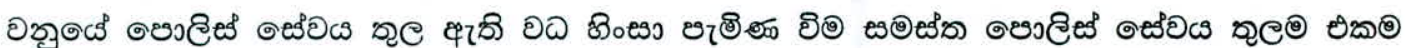

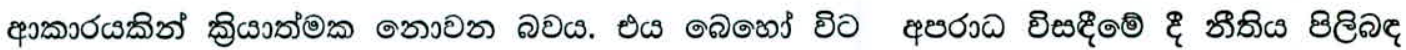

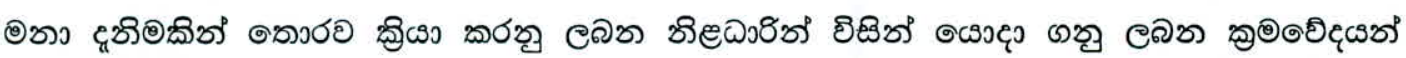

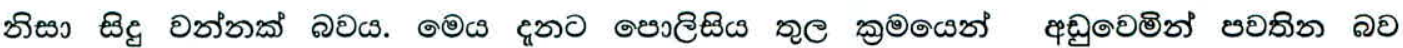

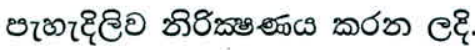

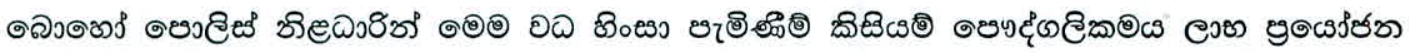

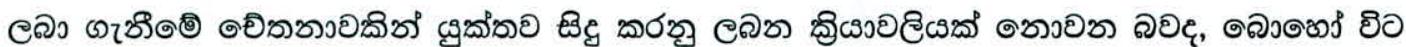

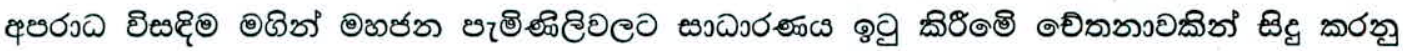

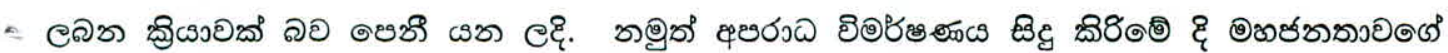

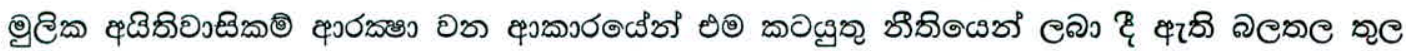




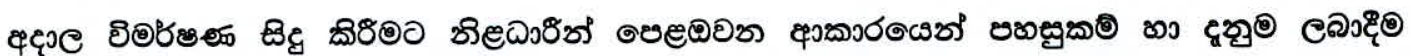

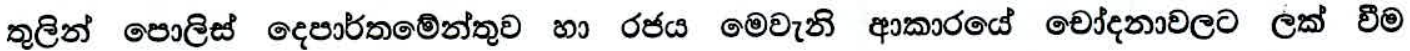

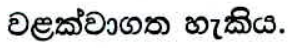




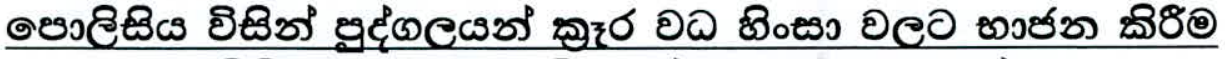

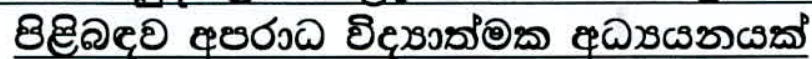

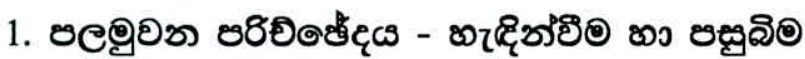

\begin{tabular}{|c|c|c|}
\hline 1.1 & อ๐ณาณைอ & 01 \\
\hline 1.2 & 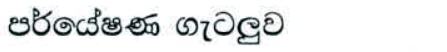 & 02 \\
\hline 1.3 & ఆరఠృరఠడ & 03 \\
\hline 1.4 & బ్రఅఠరిక్డి & 03 \\
\hline & అ્ગળ & 03 \\
\hline & 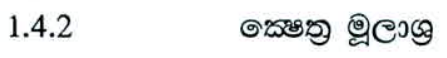 & 04 \\
\hline 1.5 & દివి ๔టో దిరి & 04 \\
\hline 1.6 & 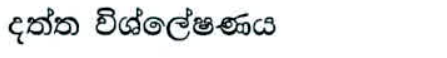 & 05 \\
\hline 1.7 & 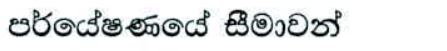 & 6 \\
\hline
\end{tabular}

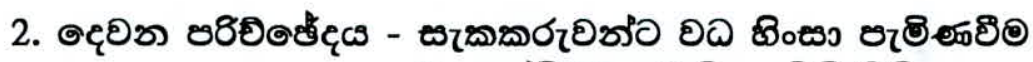

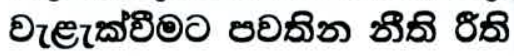

2. ऊદ్ุయాలెఠ 07

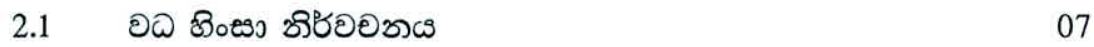

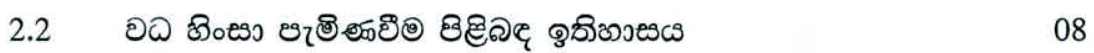

2.3 อ ऊెంเి อళธ 11

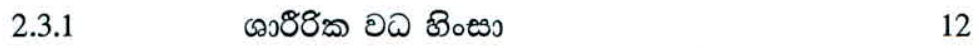

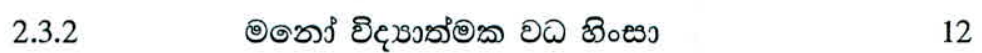

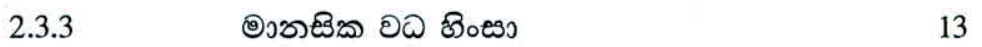

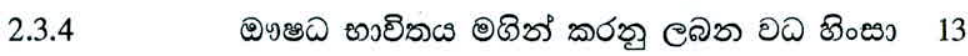

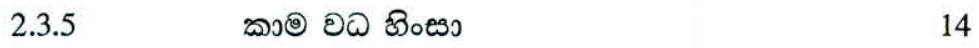

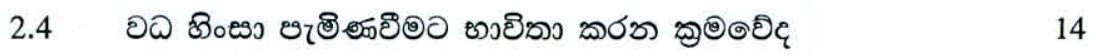

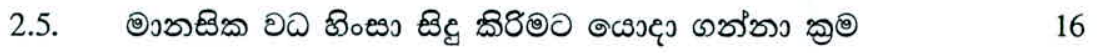



อద ऊింటి టిद्व నిరి

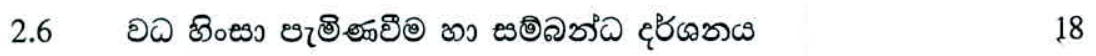

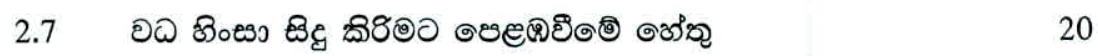

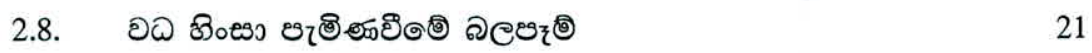

2.9. อ

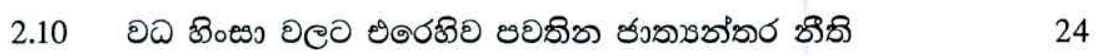

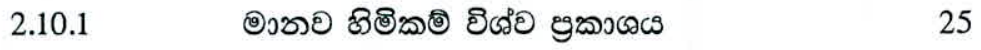

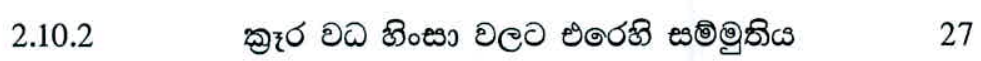

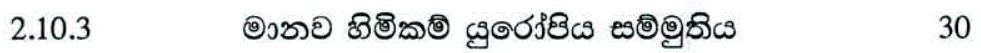

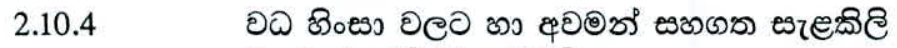

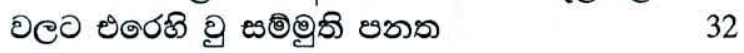

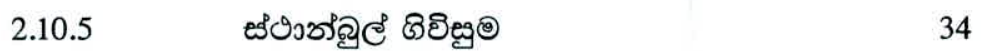

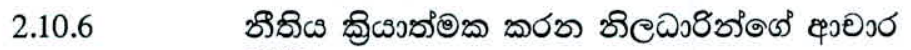
దరఠ 35

2.10.7 35

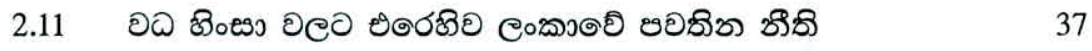

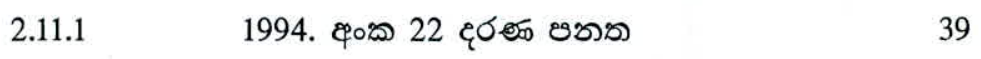

2.11.2 ஈ 41

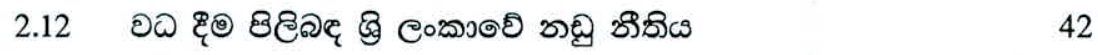

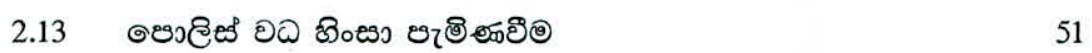

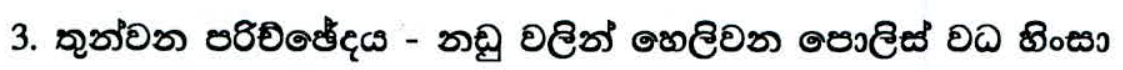

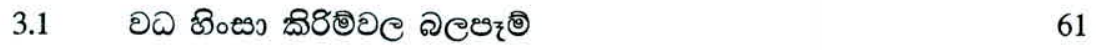

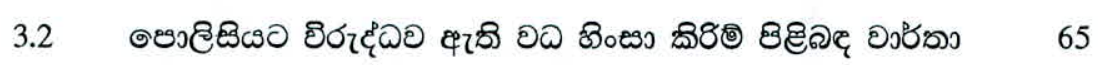

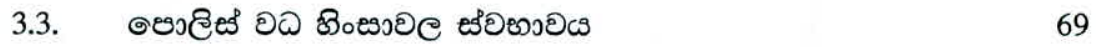




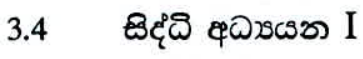

3.4.1

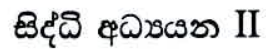

76

90

103

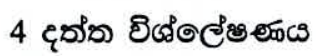

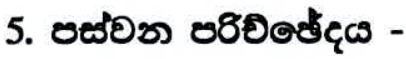

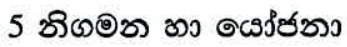

i

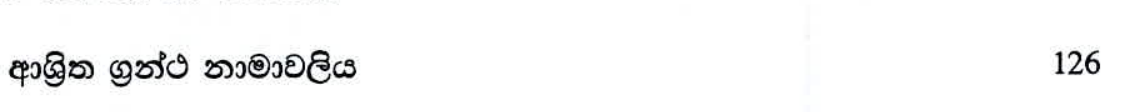

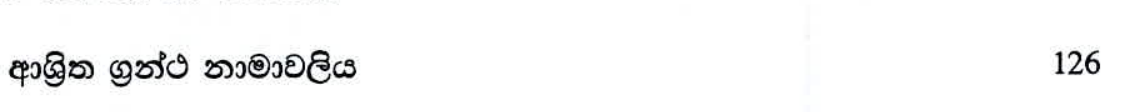

टช ๑లోవ๘డి.
1

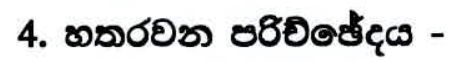

134

$f$

8 


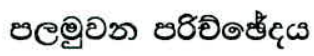

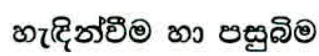

\section{1:1 องเมองอ}

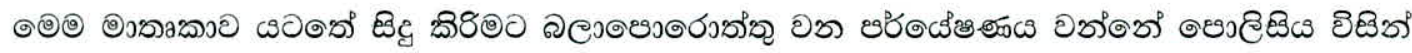

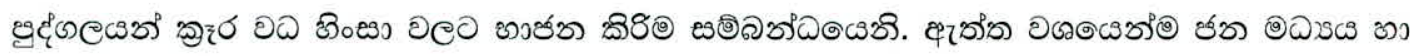

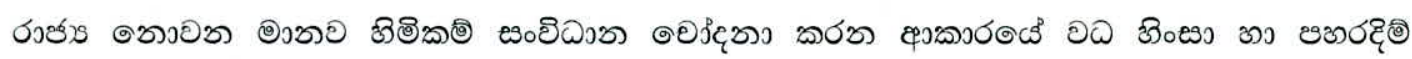

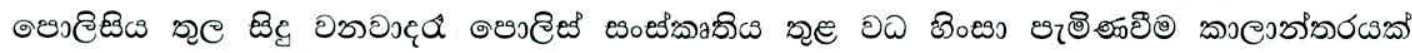

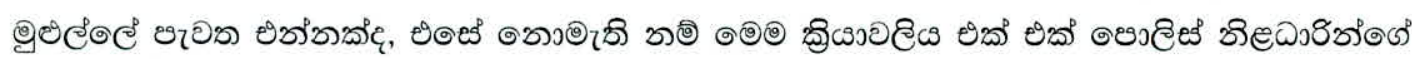

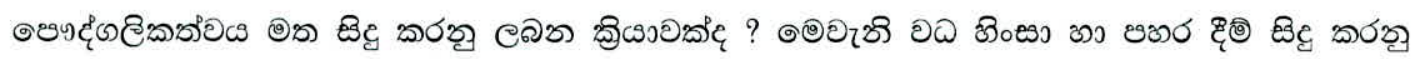

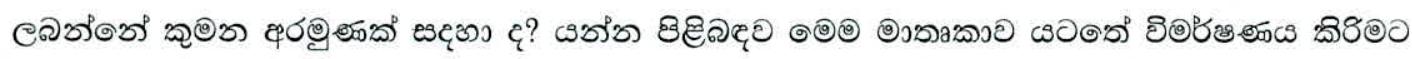

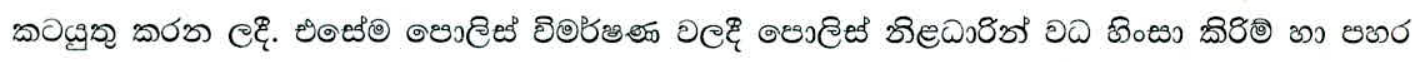

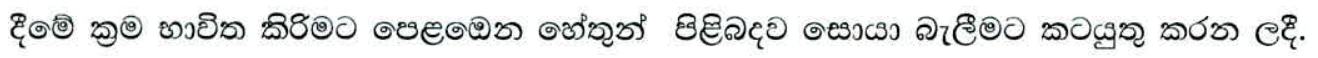

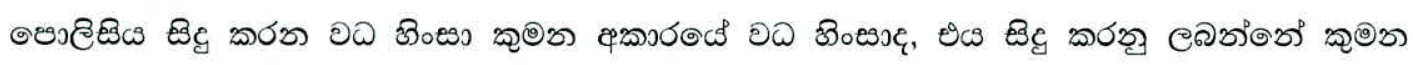

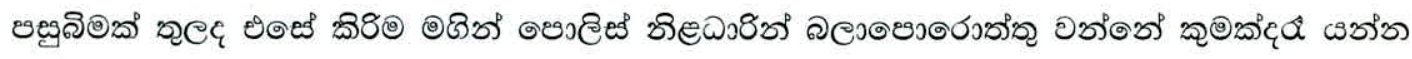

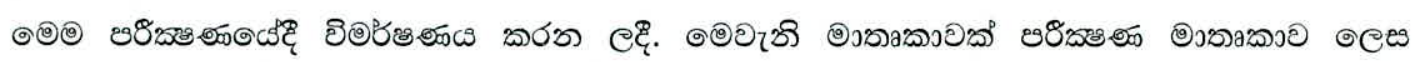

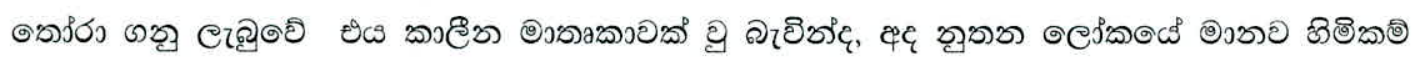

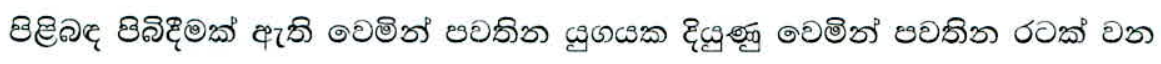

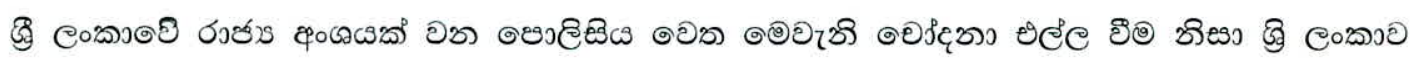

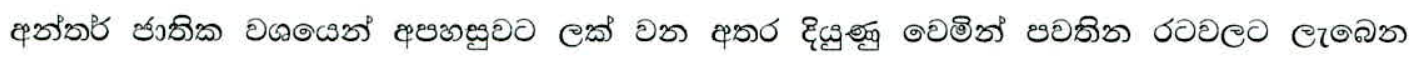

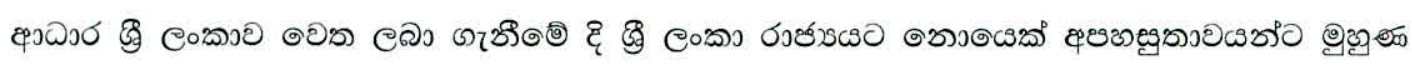

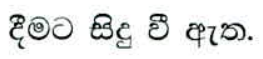




\section{2 obocis nroge}

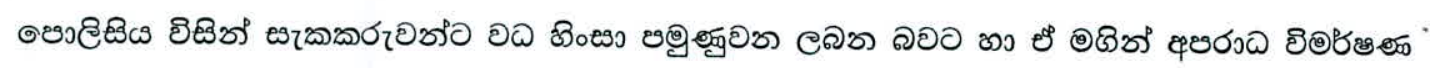

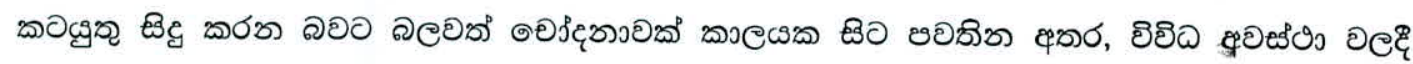

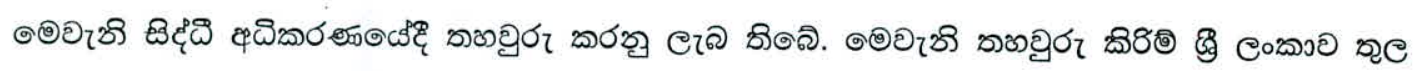

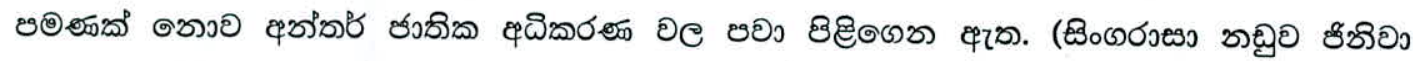

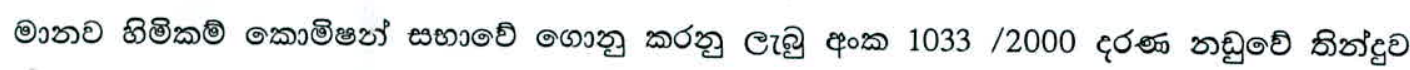
๘ร2อ)

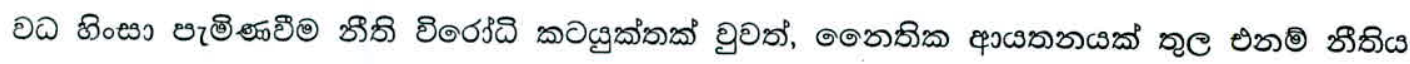

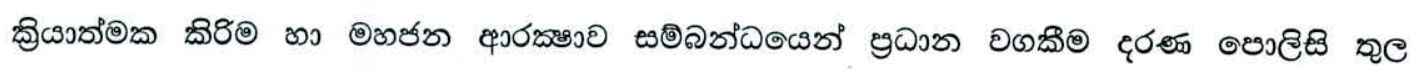

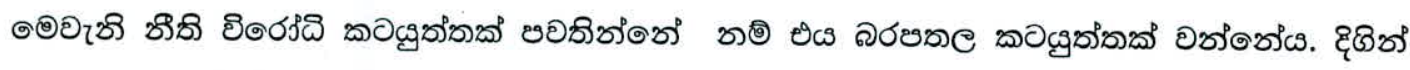

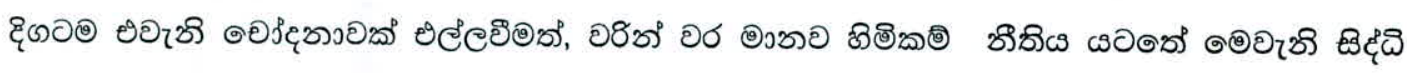

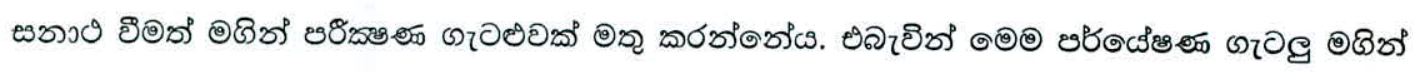

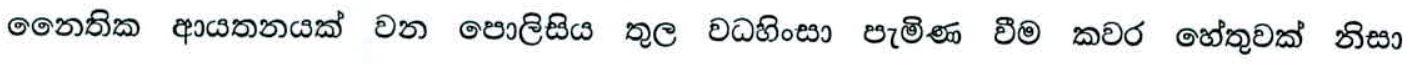

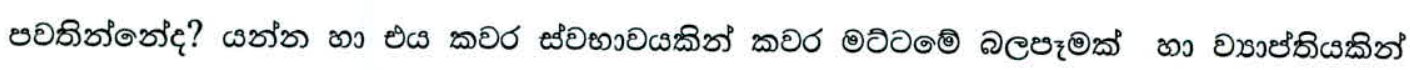

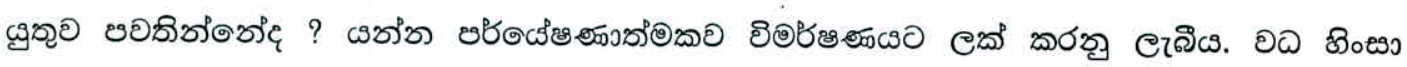

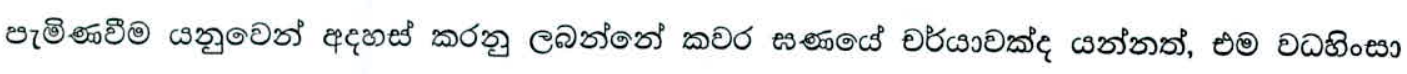

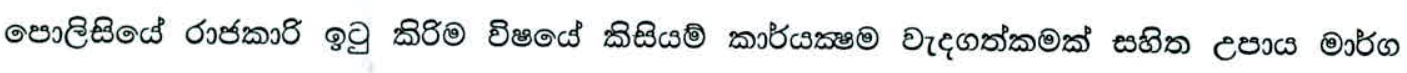

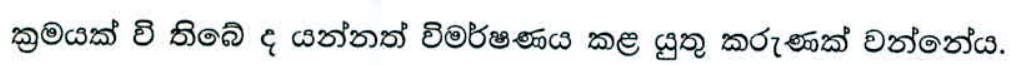

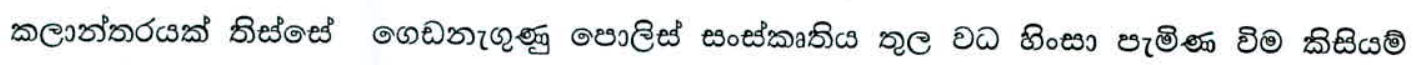

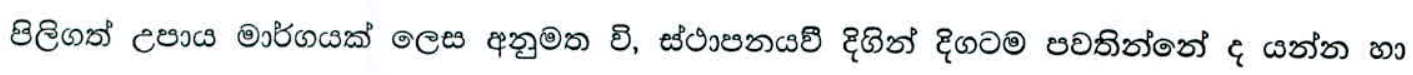

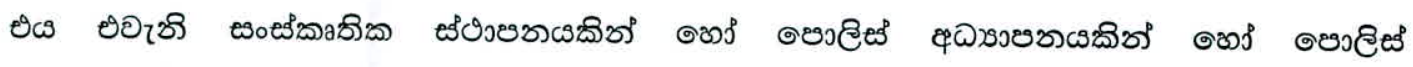

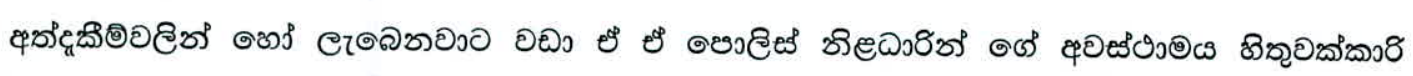

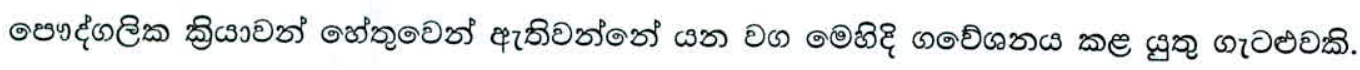




\section{$\underline{183800 j 60 \omega}$}

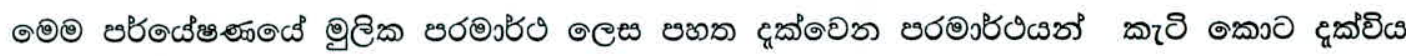

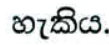

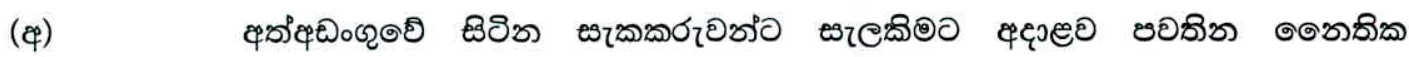

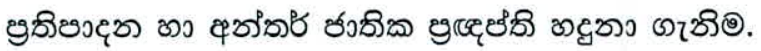

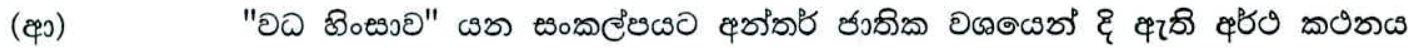

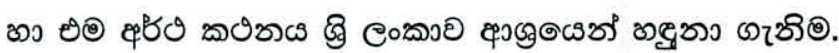

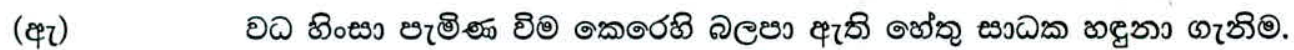

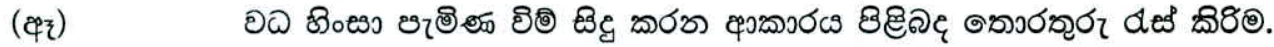

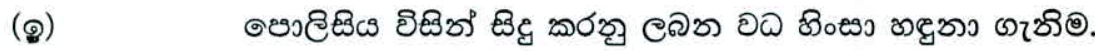

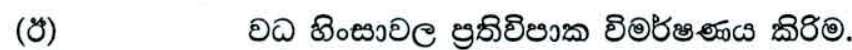

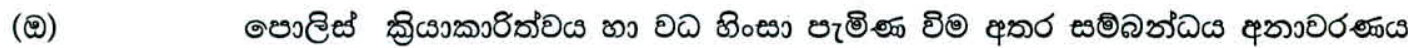
เి8๑.

184 వூరఠఠరిడ̨)

18481 అలrg

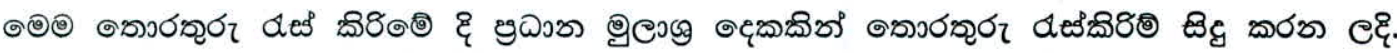

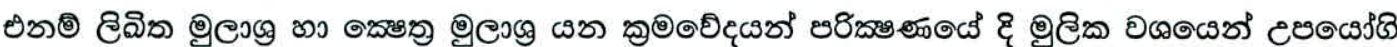

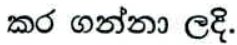

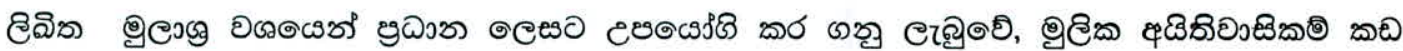

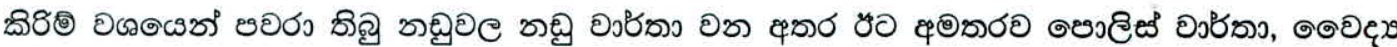

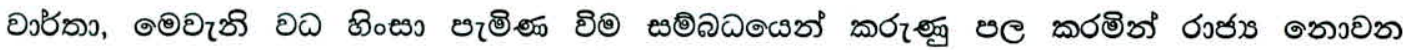

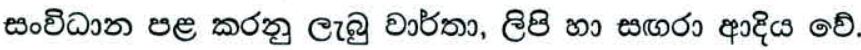




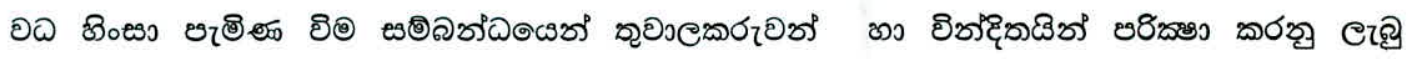

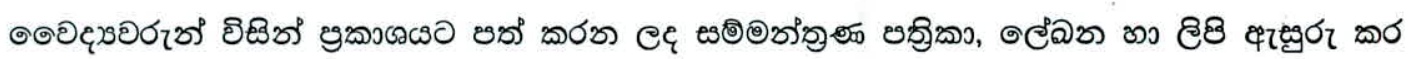

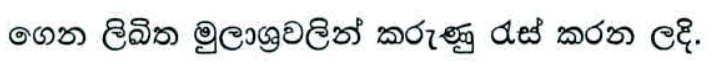

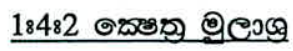

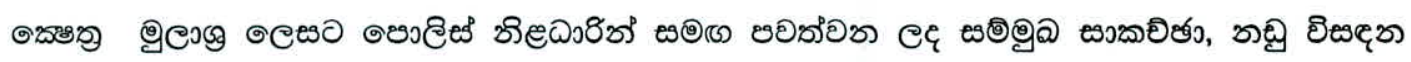

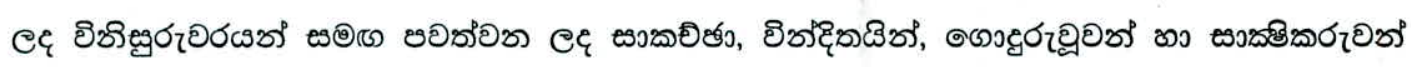

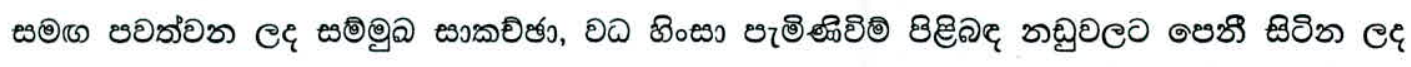

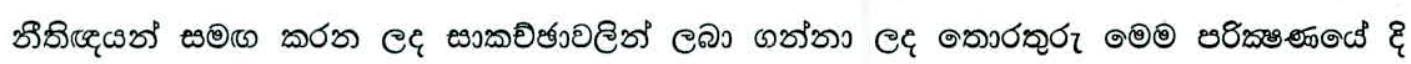

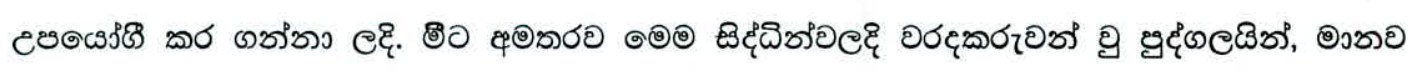

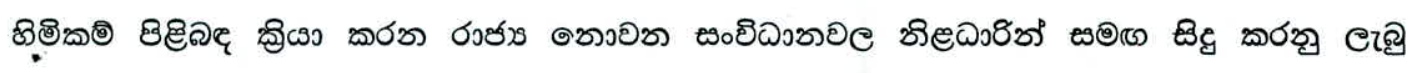

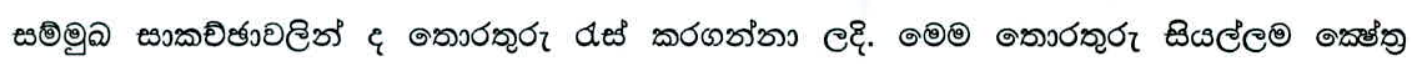

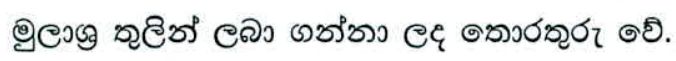

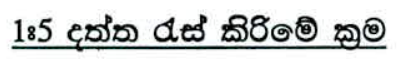

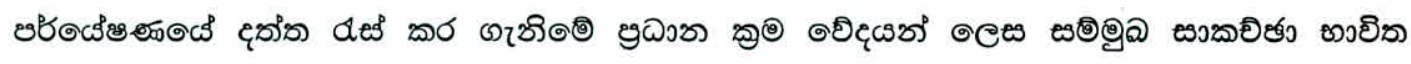

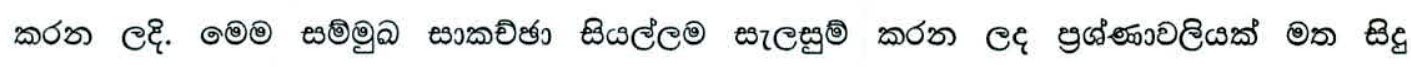

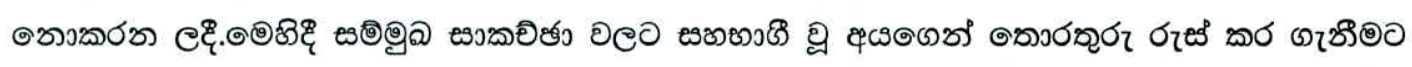

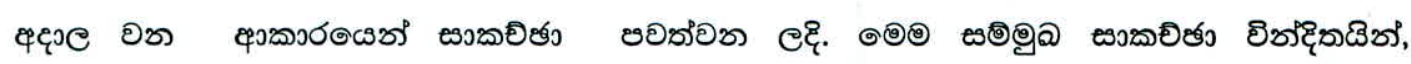

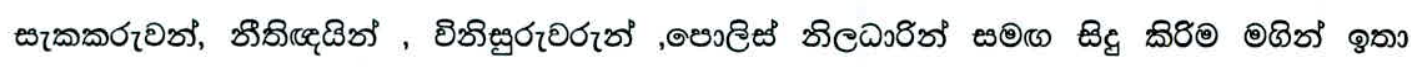

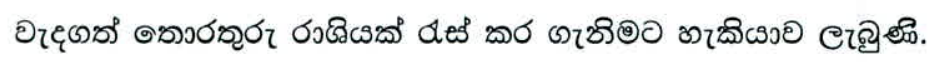

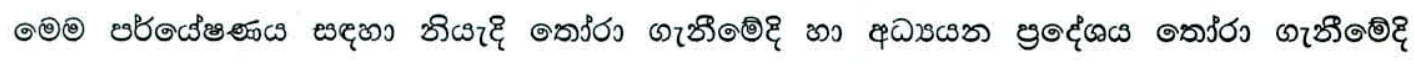

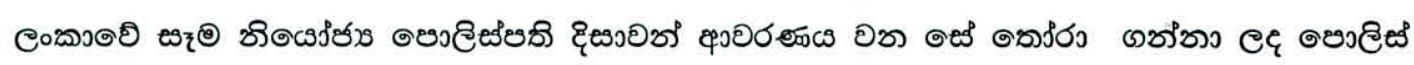

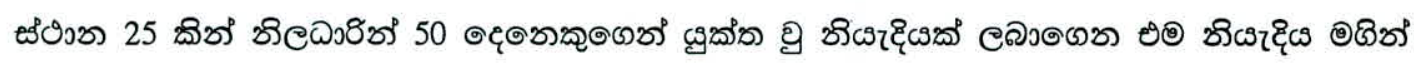

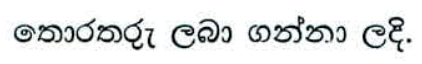

